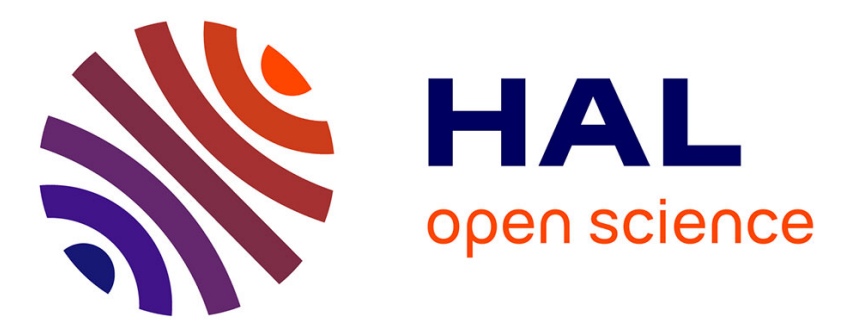

\title{
Flexural quasi-static and fatigue behaviours of fused filament deposited PA6 and PA12 polymers
}

Svetlana Terekhina, Tatiana Tarasova, Sergey Egorov, Innokentiy Skornyakov, Laurent Guillaumat, Lamine Hattali

\section{- To cite this version:}

Svetlana Terekhina, Tatiana Tarasova, Sergey Egorov, Innokentiy Skornyakov, Laurent Guillaumat, et al.. Flexural quasi-static and fatigue behaviours of fused filament deposited PA6 and PA12 polymers. International Journal of Advanced Manufacturing Technology, 2021, 117 (7-8), pp.2041-2048. 10.1007/s00170-021-07223-y . hal-03470957

\section{HAL Id: hal-03470957 https://hal.science/hal-03470957}

Submitted on 8 Dec 2021

HAL is a multi-disciplinary open access archive for the deposit and dissemination of scientific research documents, whether they are published or not. The documents may come from teaching and research institutions in France or abroad, or from public or private research centers.
L'archive ouverte pluridisciplinaire HAL, est destinée au dépôt et à la diffusion de documents scientifiques de niveau recherche, publiés ou non, émanant des établissements d'enseignement et de recherche français ou étrangers, des laboratoires publics ou privés. 


\title{
Flexural quasi-static and fatigue behaviours of fused filament deposited PA6 and PA12 polymers
}

\author{
Terekhina Svetlana ${ }^{1} \cdot$ Tarasova Tatiana $^{2} \cdot$ Egorov Sergei $^{2} \cdot$ Skornyakov Innokentiy $^{2} \cdot$ Guillaumat Laurent $^{1}$. \\ Hattali Lamine ${ }^{3}$
}

\begin{abstract}
The present paper aims to compare study the effect of porosity and degree of crystallinity on both quasi-static and fatigue behaviours of PA6 and PA12 specimens obtained by the fused filament fabrication (FFF). The glass transition and melting temperatures were measured complementary to understand better the process. Fatigue analysis is here described in visco-elastic domain of material. The results highlight that the mechanical and fatigue properties of PA 12 are better than those of PA6, in spite of almost amorphous state of PA12. Besides, porosity did not reveal the expected influence on these properties. The obtained results are also compared with conventional techniques given by the literature review.
\end{abstract}

Keywords Polyamide $6 \cdot$ Polyamide $12 \cdot$ Fused filament fabrication $\cdot$ Fatigue $\cdot$ Mechanical properties

\section{Introduction}

The additive manufacturing has become a mainstream in a wide range of industries from biomedical equipment to the aerospace field. Among a multitude of additive processes, one of the most promising technologies for polymers is the

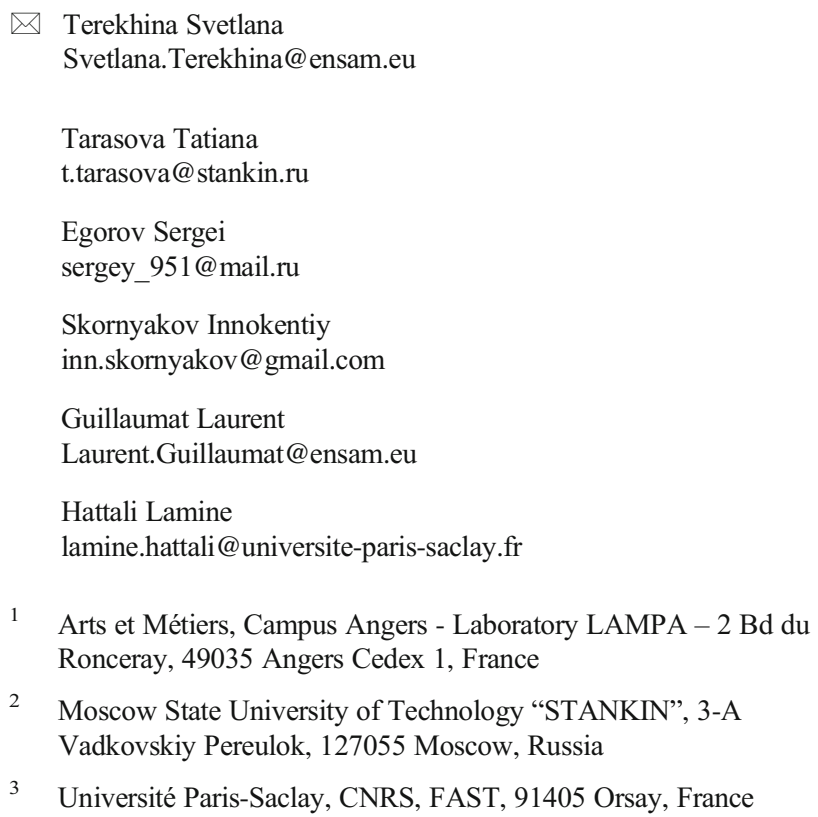

3 Université Paris-Saclay, CNRS, FAST, 91405 Orsay, France

method of fused filament fabrication (FFF). It is an additive manufacturing process that belongs to the material extrusion family. In FFF, an object is built by selectively depositing melted material in a pre-determined layer-by-layer path [1]. The advantages of the method are simplicity and low cost of equipment and maintenance.

While AM provides the opportunity to quickly go from design to product especially for parts that have difficult or impossible to machine features, challenges remain for predicting mechanical performance. According to various sources [2-10], FFF printing involves an extremely large number of process parameters that the most important are (i) raster orientation, (ii) layer height, (iii) layer thickness, (iv) extruder temperature, (v) feed rate, (vi) gap between raster, and (vii) build orientation. All of them have the potential to impact the mechanical properties of the finished part.

Typical printing materials cited in the literature are polylactic acid (PLA), acrylonitrile butadiene styrene (ABS), and polycarbonate $(\mathrm{PC})$. There is a lack in the literature regarding the quasi-static flexural and its fatigue behaviours of some semi-crystalline materials like polypropylene (PP), polyamides (PA), and polyether ether ketone (PEEK) within FFF process. A key reason for their limited use is attributed to their severe shrinkage and warpage that occurs during part cooling and crystallization. Polymers with high crystallinity distort and warp more during FFF process, in comparison with amorphous plastics, due to the considerable volume reduction 
associated with the formation of ordered, more densely packed regions during crystallization [11-13]. However, PA12 and PA6 are well-known by its excellent mechanical and chemical properties, highlighting their potential use for the new industrial applications, obtained by the FFF process. Besides, the PA12 manifests biocompatibility and has very low water absorption compared to other nylons (like PA6), giving it more attractive.

The aim of this research is to study the effect of porosity and degree of crystallinity on both quasi-static and fatigue behaviours of PA6 and PA12 specimens obtained by the FFF process. It is well known that the part build orientation and raster orientation are parameters with great influence on the mechanical properties of the printed material. They present a synergetic interaction between them; i.e., the part build orientation modifies the raster orientation. Consequently, for simplification reason, all specimens were printed with the raster orientation of $0^{\circ}$, i.e., unidirectional. After conducting many experimental trial runs and based on the previous published results $[14,15]$, there were chosen FFF process to print the part in $X Z$ plane build orientation (On-edge), which presents the best mechanical properties compared to $X Y$ (Flat) and $Y Z$ (up-right) plane build orientations. In this analysis, the results are also compared to conventional processes data given by the literature review.

\section{Materials and FFF process}

The polyamide 6 (PA6) and polyamide 12 (PA12) used in this study for the FFF process are the thermoplastic filaments NYLON 230 and STYX-12 produced by Taulman (USA) and Formfutura (Netherlands) respectively. NYLON 230 is a standard polyamide 6 without chemical additive. One big challenge with PA6 filaments is that they are hygroscopic, which means they readily absorb moisture from their surroundings. Based on polyamide PA12, the STYX-12 ${ }^{\mathrm{TM}}$ is an industrial nylon filament that combines excellent mechanical, chemical, and hygroscopic properties with printability. The STYX $-12^{\mathrm{TM}}$ has a very low water absorption compared to PA6. This combination of properties has resulted in high-performance and industrial-grade nylon which can be printed on a wide-range of FFF/FDM 3D printers. However, it is recommended to dry material before each printing. To overcome the problem of moisture, the drying of the filaments before printing was carried out at $60^{\circ} \mathrm{C}$ in a vacuum oven for $6 \mathrm{~h}$. This time is required to stabilize the weight loss of the filament. All the specimens were then stored in the dry atmosphere of a desiccator prior to testing. Material properties given by manufacturers are summarized in Table 1 for PA12 and PA6 respectively. The specimens of FFF process were manufactured on the open-source Spiderbot 3D printer (Fig. 1a).
Simplify3D software version 4.1 was used for slicing the .STL files into machine readable g-code.

Rectangular specimens intended for standard quasi-static flexural and fatigue mechanical analyses were directly fabricated. The dimension of which is $100 \times 20 \times 4 \mathrm{~mm}^{3}$. Figure $1 \mathrm{~b}$ shows STL file of the three-point bending test specimen conforming to the ISO 178:2010 [16], printed in the $X Z$ plane build direction. Table 2 summarizes the important printing parameters used in the FFF process.

\section{Experimental procedure}

\subsection{Differential scanning calorimetry}

The thermal properties of PA12 and PA6 polymers were analyzed by differential scanning calorimetry (DSC) on a DSC404 F1 machine (Netzsch, Germany). Test specimen fragments (length and width $\sim 1 \mathrm{~mm}$, thickness $\sim 200 \mu \mathrm{m}$ ) were carefully cut by scissors from the bottom supportive layer of specimens used in quasi-static mechanical tests. Each sample weighed $8-10 \mathrm{mg}$. Heating/cooling rate $\mathbf{k}$ of $10^{\circ} \mathrm{C} / \mathrm{min}$ from 25 to $350{ }^{\circ} \mathrm{C}$ in argon atmosphere was chosen according to ASTM D3418 [17]. This data was used to generate a graph of the heat flux versus temperature. Three specimens were tested. The glass transition $\left(T_{g}\right)$, melting temperature $\left(T_{m}\right)$, and crystal weight fraction $(X c)$ of the specimens were measured after the additive process. The $X c$ was determined by

$X_{c}=\frac{\left(\Delta H_{m}-\Delta H_{c c}\right)}{\Delta H_{m 0}}$

where $\Delta H_{m}$ is the area under the melting endotherm, $\Delta H_{c c}$ is the area under the cold crystallization/recrystallization curve, and $\Delta H_{m 0}$ is the heat of fusion for $100 \%$ crystalline sample $(245 \mathrm{~J} / \mathrm{g}$ and $230 \mathrm{~J} / \mathrm{g}$ for PA12 and PA6 respectively [18]).

\subsection{Determination of porosity}

Density is obtained by weighing the cut PA6 and PA12 specimens before and after impregnation with diiodomethane $\left(\mathrm{CH}_{2} \mathrm{I}_{2}\right)$ [19] and determination of their volume from the Archimedes force:

$\rho=\frac{m_{a}}{m_{a\left(\mathrm{CH}_{2} \mathrm{I}_{2}\right)}-m_{\mathrm{H}_{2} \mathrm{O}\left(\mathrm{CH}_{2} \mathrm{I}_{2}\right)}} \rho_{\left(\mathrm{H}_{2} \mathrm{O}\right)}$

where $m_{a}, m_{a(\mathrm{CH} 2 \mathrm{I} 2)}$, and $m_{\mathrm{H} 20(\mathrm{CH} 2 \mathrm{I2})}$ are the specimens weighed in air, diiodomethane, and water with diiodomethane respectively; $\rho_{(\mathrm{H} 2 \mathrm{O})}$ is the density of water. Note that the impregnation with diiodomethane, which is a compound 
Table 1 Material properties of PA12 and PA6 polymers given by the manufacturers

\begin{tabular}{lll}
\hline Material (Process) & PA6 (Nylon 230, FFF) & PA12 (STYX-12 $\left.{ }^{\mathrm{TM}}, \mathrm{FFF}\right)$ \\
\hline Chemical formula & {$\left[\mathrm{NH}-\left(\mathrm{CH}_{2}\right)_{5}-\mathrm{CO}\right]_{\mathrm{n}}$} & {$\left[-\mathrm{NH}-\left(\mathrm{CH}_{2}\right)_{11}-\mathrm{CO}-\right]_{\mathrm{n}}$} \\
Diameter (mm) & 1.75 & 1.75 \\
Melting temperature: $T_{m},{ }^{\circ} \mathrm{C}$ & 195 & $250 \pm 10$ \\
Glass transition temperature: $T_{g},{ }^{\circ} \mathrm{C}$ & 68 & 132 \\
Tensile modulus when 3D printed, $\mathrm{MPa}$ & 730 & 1400 \\
Tensile strength when 3D printed, $\mathrm{MPa}$ & 34 & 60 \\
Coefficient of thermal expansion $\left(\times 10^{-6} \mathrm{~K}^{-1}\right)$ & 95 & 100 \\
Water absorption $(\%$ weight increase, saturated) & $8.5-10$ & 1.6 \\
Density, $\mathrm{g} / \mathrm{cm}^{3}$ & 1.14 & 1.02 \\
\hline
\end{tabular}

immiscible with water, prevents water to penetrate into open pores of the specimens.

Thus, the true measured porosity is expressed by

$$
\rho=\frac{m_{a}}{m_{a\left(\mathrm{CH}_{2} \mathrm{I}_{2}\right)}-m_{\mathrm{H}_{2} \mathrm{O}\left(\mathrm{CH}_{2} \mathrm{I}_{2}\right)}} \rho_{\left(\mathrm{H}_{2} \mathrm{O}\right)}
$$

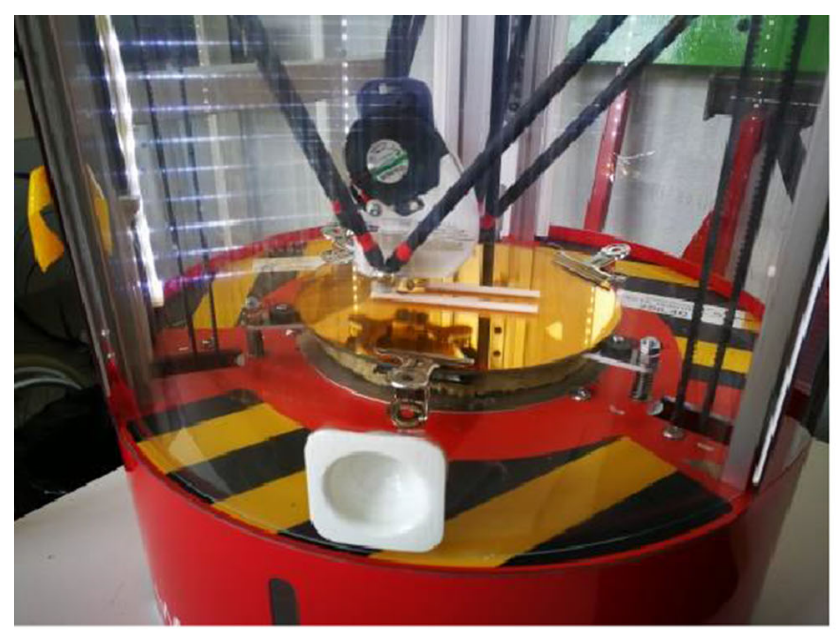

(a)

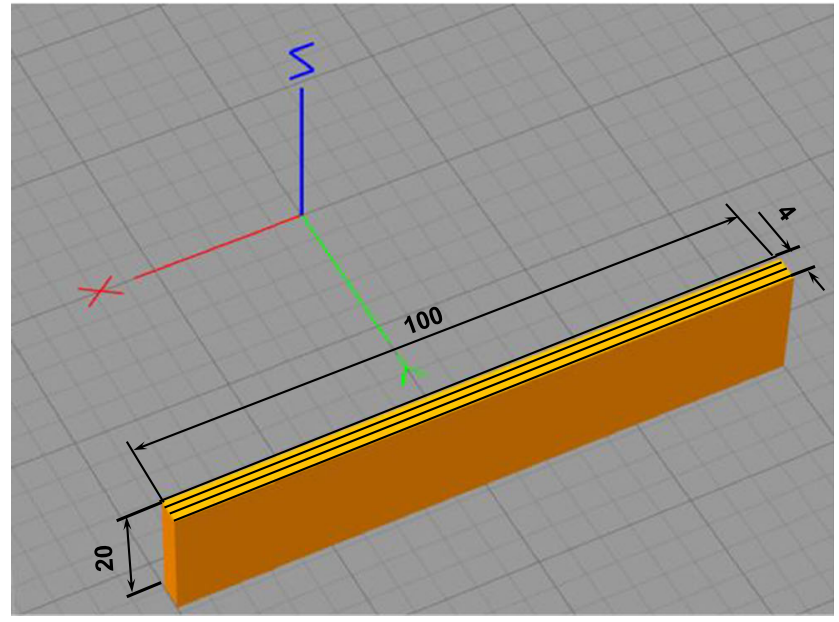

(b)

Fig. 1 a FFF open-source Spiderbot 3D printer. b Printing direction configurations for FFF process, using Simplify3D where $\rho_{s}$ is the density of the initial material.

\subsection{Mechanical characterization}

Quasi-static flexural mechanical property tests were conducted in the three-point-bending mode according to the ISO 178:2010 standard for $X Z$ build orientation of the unidirectional PA6 and PA12 specimens. The tests were carried out to establish an elastic flexural modulus $\left(E_{f}\right)$, elastic limit stress $\left(\sigma_{\text {el. } f}\right)$, and ultimate flexural strength $\left(\sigma_{\text {max. } f}\right)$. The distance between the two support pins was $L=80$ $\mathrm{mm}$. The ratio $L / h$ was equal to 20 , which allows ignoring the shear stresses during testing. The tests were carried out on an electro-mechanical testing machine (Zwick) under the displacement controlled conditions at a constant rate of 100 $\mathrm{mm} / \mathrm{min}$ (Fig. 2a). At least five specimens of each build orientation were tested.

Three-point bending cyclic tests were performed on a setup designed at LAMPA laboratory (Fig. 2b). The same specimen dimensions and span length as for the quasi-static testing were used.

The fatigue tests were displacement-controlled with various strain ratios $r$ defined by

$r=\frac{\varepsilon_{\max }}{\varepsilon_{\mathrm{el}}}$

with $\varepsilon_{\max }$ and $\varepsilon_{\mathrm{el}}$, respectively, the maximal strain applied during the fatigue tests and the average elastic strain measured during quasi-static tests. Note that to reduce maximum the visco-plastic behaviour of materials during the fatigue tests, all the specimens tested were conducted in their visco-elastic domain (below yield point). Since there is currently no material standard for additive manufactured parts, the recommendation from a similar material standard for the flexural fatigue properties of plastics was used [20]. The tests were performed with a frequency of $5 \mathrm{~Hz}$. The temperature of the specimen was not significantly affected by this frequency; the observed change in temperature was much smaller than the recommended maximum temperature rise of $10^{\circ} \mathrm{C}[8,14,15]$. The 
Table 2 Fixed FFF process parameters along with their nominal values

\begin{tabular}{lll}
\hline & Printing parameters of PA6 & Printing parameters of PA12 \\
\hline Colour filament & Colourless & Colourless \\
Print speed, mm/min & 2250 & 1900 \\
Movement speed, mm/min & 5400 & 5400 \\
$T_{\text {bed, }}{ }^{\circ} \mathrm{C}$ & 90 & 100 \\
$T_{\text {head, }}{ }^{\circ} \mathrm{C}$ & 230 & 245 \\
Extrusion width & 0.67 & 0.67 \\
Layer height, mm & 0.2 & 0.2 \\
Nozzle diameter, mm & 0.5 & 0.5 \\
Extrusion multiplier & 1 & 1 \\
Overlap, $\%$ & 40 & 40 \\
Number of contours & 3 & 3 \\
Infill percentage, $\%$ & 100 & 100 \\
Raster orientation, ${ }^{\circ}$ & 0 & 0 \\
\hline
\end{tabular}

tolerable threshold was taken as a temperature rise $<10{ }^{\circ} \mathrm{C}$ relative to ambient conditions. At least three specimens per loading configuration were tested. The experimental program is summarized in Table 3.

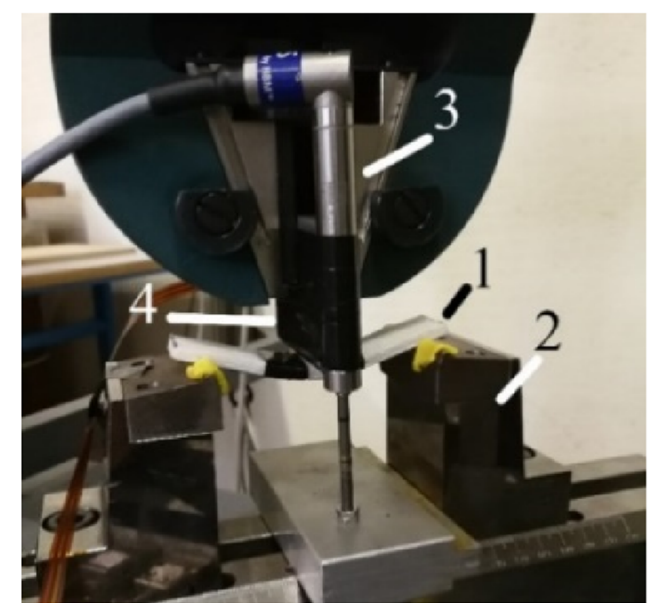

(a)

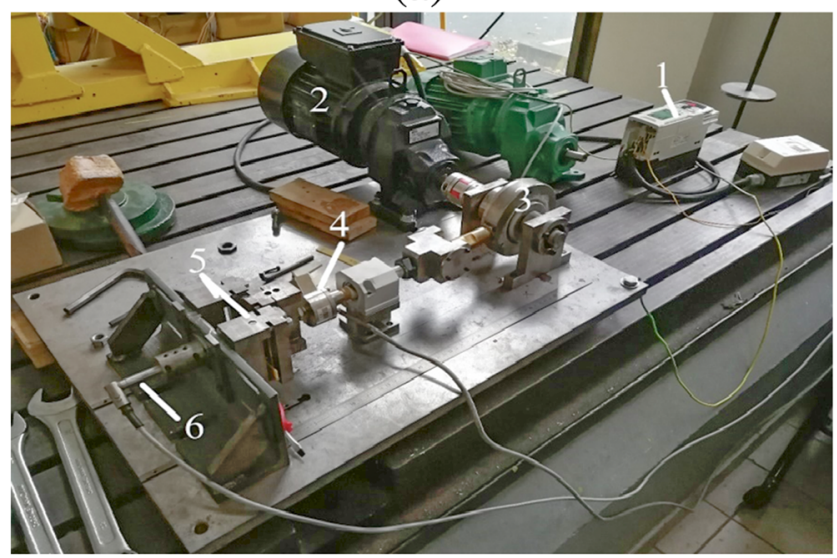

(b)

Fig. 2 a Zwick testing machine: 1-specimen, 2-support, 3displacement sensor, 4- punch. b Experimental fatigue setup: 1frequency controller, 2-engine, 3-eccentric, 4-load cell, 5-support, 6 - displacement sensor LVDT

\section{Results and discussion}

\subsection{Thermal and physical properties}

The properties of plastics are significantly influenced by their degree of crystallization [21]. The higher the degree of crystallization, the stiffer and stronger, but also more brittle a printed part is [22]. Above a critical threshold, it causes the warping [14]. The DSC analysis can also provide valuable information about the thermal transitions, crystalline melting enthalpies, and cold crystallization/recrystallization. Therefore, to understand and compare the mechanical properties of both studied polymers after the FFF

process, it is necessary to know their thermal properties.

Figures $3 \mathrm{a}$ and $\mathrm{b}$ show a DSC graph of heat flux $(\mathrm{mW} / \mathrm{mg})$ versus temperature $\left({ }^{\circ} \mathrm{C}\right)$ for studied specimens. The spectrums show clear evidence of cold crystallization (at $\sim 180^{\circ} \mathrm{C}$ ) in the case of PA12, a process associated to crystallization of the amorphous segments in the polymer above the glass transition temperature (Fig. 3a). It could be supposed that the FFF filament was quenched by the manufacturer to facilitate the FFF printing process. Table 4 summarizes the obtained results that

Table 3 Experimental conditions for fatigue tests

Materials

\begin{tabular}{lllllll}
\hline PA6 & $\varepsilon_{\max }, \%$ & 0.3 & 0.6 & 0.9 & 1.2 & 1.5 \\
PA12 & $r, \%$ & 14 & 27 & 41 & 55 & 68 \\
& & - & - & & & \\
& No. of specimen tested per material & 3 & 3 & 3 & 3 & 3 \\
\hline
\end{tabular}


reveal the degree of crystallinity of the PA6 specimens to be four times higher than the PA12 ones.

Only $5 \%$ of crystallinity is obtained in the latter. In addition, the glass transition and melting temperatures were $253^{\circ} \mathrm{C}$ and $132^{\circ} \mathrm{C}$, and $214^{\circ} \mathrm{C}$ and $73^{\circ} \mathrm{C}$ for the PA12 and PA6 respectively.

Part density and porosity are important parameters to investigate as they are intrinsic to FFF parts printed. The average porosity and density of PA6 and PA12 obtained by the FFF process in XZ build orientation are summarized in Table 5. The obtained results show that there is no difference in porosity for the studied materials, printed in the same build orientation. Based on the previous studies, only the type of process and its parameters influence on the latter $[14,15]$.

\subsection{Quasi-static flexural and fatigue behaviours}

Stress-strain curves are plotted in Fig. 4a for respectively PA12, and PA6 specimens obtained after the FFF in $X Z$ build orientation. Table 6 and Figure 4 a summarize the observed difference between two materials. The printed PA6 specimens are four times less resistant than the PA12 ones. The latter are three times stiffer than the PA6 ones, despite their four times lower degree of crystallinity. The worth mechanical properties of printed PA6 is explained either by lower degree of crystallinity (20\%) obtained during the printing that is generally about $40 \%$ for IM and extruded specimens or by the possible chemical modifications of filament Nylon 230, in order to give it a good printability. However, the flexural modulus of printed PA12 is $\sim 6.5 \%$ and $\sim 25 \%$ better than the PA12 manufactured by IM and extruded processes respectively. Besides, flexural maximum stresses are similar to those obtained by considered conventional processes. Note that all studied materials were not failed after a significant deflection (more than 10\% strain) and thus are considered as "ductile." Satisfactory repeatability is achieved for all performed tests, with bending properties scattering that does not exceed $10 \%$.

The endurance diagram was plotted to determine the end of life according to an $\mathrm{N}_{10}$ criterion for different loading ratios $\mathrm{r}$ (Fig. 4b). This criterion is satisfied when a $10 \%$ decrease in the mechanical properties is noticed. The $\mathrm{N}_{10}$ criterion was chosen because under three-point-bending fatigue with imposed displacement, a breakage of the PA6 and PA12 specimens has

Table 4 Average values of 3 DSC analyses

\begin{tabular}{lccccc}
\hline Material & $T_{g},{ }^{\circ} \mathrm{C}$ & $\Delta H_{m}, \mathrm{~J} / \mathrm{g}$ & $\Delta H_{c c}, \mathrm{~J} / \mathrm{g}$ & $X_{c}, \%$ & $T_{m},{ }^{\circ} \mathrm{C}$ \\
\hline PA12 & $132 \pm 1$ & $25 \pm 0.2$ & $13.8 \pm 0.2$ & $5 \pm 0.5$ & 253 \\
& & & & & \pm 1.2 \\
PA6 & 73 & $46 \pm 0.4$ & - & 20 & 214 \\
& $\pm 2 .-$ & & & $\pm 0 .-$ & \pm 0.5 \\
& 5 & & & 2 & \\
\hline
\end{tabular}

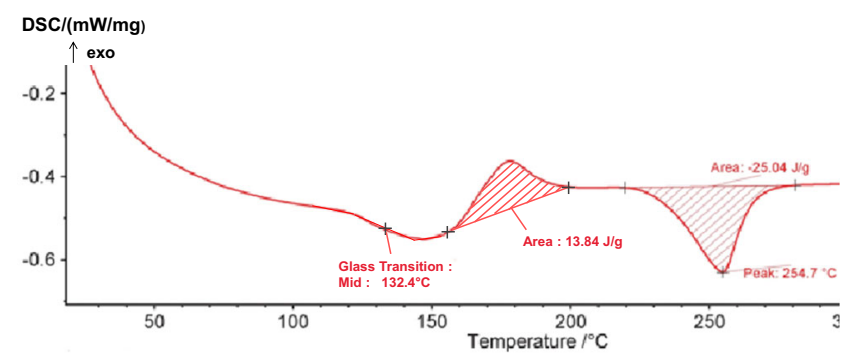

(a)

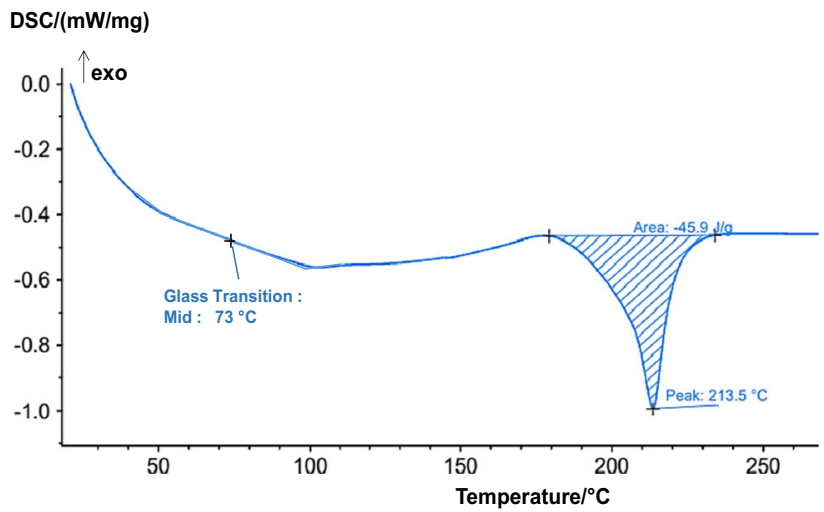

(b)

Fig. 3 An example of typical DSC data for a PA12 and b PA6 materials after the FFF process

never been observed. Besides, 3D printing creates anisotropic specimens, as in the case of composites [32], and, therefore, the large dispersion at the end-of-life. It seems that the fatigue properties of PA12 have never reached the $\mathrm{N}_{10}$ criterion at loading ratios and fixed FFF parameters applied contrary to PA6 specimens. Although the PA6 is more crystalline when compared to PA12, the latter has a higher overall fatigue life. However, the operating range of the fatigue machine did not allow a detailed conclusion about its fatigue properties. Lesser [33] also observed a higher overall fatigue life of polyamide compared to polyacetal despite a higher degree of crystallinity of the latter. In theory, stiffness degradation results from crack propagation and/or degradation of filament deposited. In observed case, the degradation is attributed solely to growth of micro-delamination fatigue cracks at the interface between layers at the level of the load applied (Fig. 5). Note that the PA6 is more sensible to delamination than the PA12. Based on data of the endurance diagram, a simple linear model of the fatigue properties has been developed, using the least-squares

Table 5 Average porosity and density of PA6 and PA12 specimens for FFF process in $X Z$ build orientation

\begin{tabular}{lll}
\hline & PA12 & PA6 \\
\hline Porosity $(\%)$ & $10.6 \pm 1.7$ & $11.0 \pm 1.6$ \\
Density $\left(\mathrm{g} / \mathrm{cm}^{3}\right)$ & $0.9032 \pm 0.04$ & $1.015 \pm 0.03$ \\
\hline
\end{tabular}


Table 6 Summary of quasi-static flexural test results compared with those of conventional manufacturing processes. All data was obtained at ambient temperature

\begin{tabular}{|c|c|c|c|c|c|c|c|}
\hline Material/Process & $\begin{array}{l}\text { Moisture } \\
\text { condition }\end{array}$ & $X c, \%$ & $E_{f}, \mathrm{MPa}$ & $\begin{array}{l}\sigma_{\text {el.f, }} \\
\mathrm{MPa}\end{array}$ & $\begin{array}{l}\sigma_{\max . f} \\
\mathrm{MPa}\end{array}$ & $\begin{array}{l}\varepsilon_{\mathrm{el}}, \\
\%\end{array}$ & Ref. \\
\hline PA12/ FFF & Dry & $5 \pm 0.5$ & $1472 \pm 51$ & $\begin{array}{l}41.7 \\
\quad \pm 1.4\end{array}$ & $63 \pm 2$ & 2.8 & - \\
\hline PA6/ FFF & Dry & 20 & \pm 0.2 & $500 \pm 18$ & $10 \pm 0.4$ & 16 & $\begin{array}{l} \pm 0 .- \\
6\end{array}$ \\
\hline 2.2 & - & & & & & & \\
\hline \multirow{5}{*}{$\begin{array}{l}\text { PA6/Injection moulding } \\
\text { (IM) }\end{array}$} & Dry & - & 2700 & - & $105-108$ & & {$[23$,} \\
\hline & Dry & 30 & 2750 & - & - & & 24] \\
\hline & Dry & 44 & 2800 & - & 61 & & {$[25]$} \\
\hline & $50 \% \mathrm{HR}$ & - & 966 & - & 40 & & {$[26]$} \\
\hline & & & & & & & {$[23]$} \\
\hline \multirow[t]{2}{*}{ PA6/Extrusion } & Dry & - & 3100 & - & 103 & & {$[27]$} \\
\hline & Dry & 36 & 2800 & - & 78 & & {$[28]$} \\
\hline PA12/IM & Dry & - & 1376 & - & 61 & & [29] \\
\hline \multirow[t]{2}{*}{ PA12/Extrusion } & - & - & 1300 & $10-56$ & 56 & & {$[30]$} \\
\hline & Dry & - & $900-1200$ & 50 & $50-65$ & & {$[31]$} \\
\hline
\end{tabular}

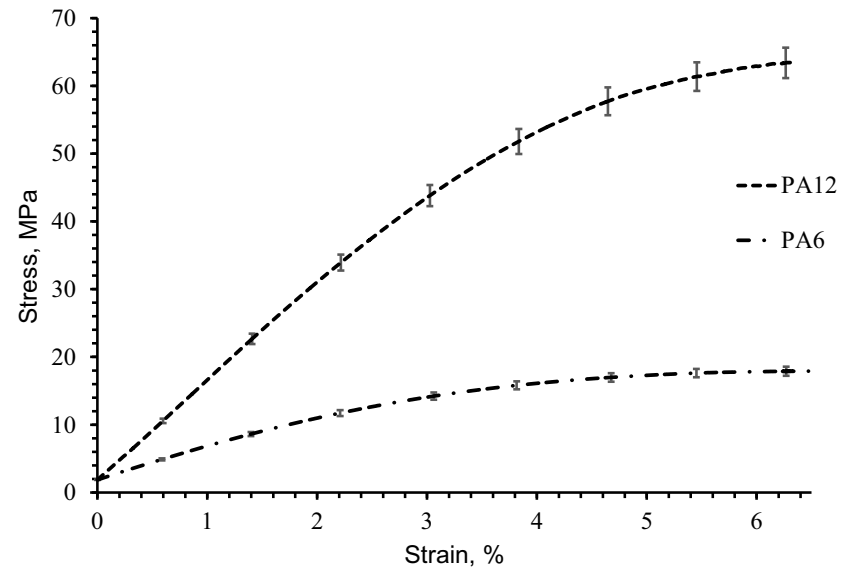

(a)

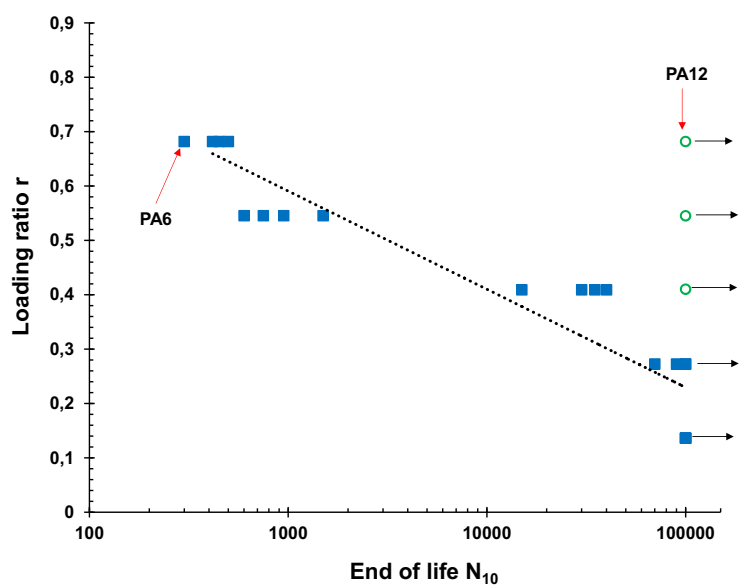

(b)

Fig. 4 Comparison of polyamide materials (PA6, PA12) after FFF process: a quasi-static flexural behaviour; $\mathbf{b}$ endurance diagram $(\rightarrow$ means that the specimen is not failed at $\mathrm{N}_{10}$ criterion)

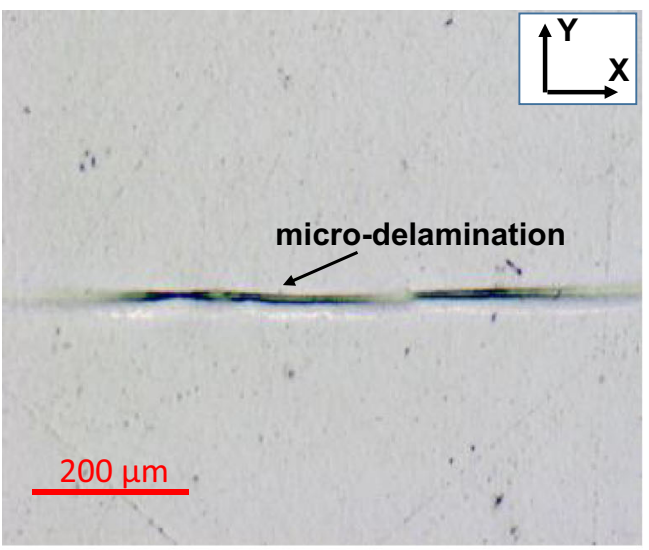

a)

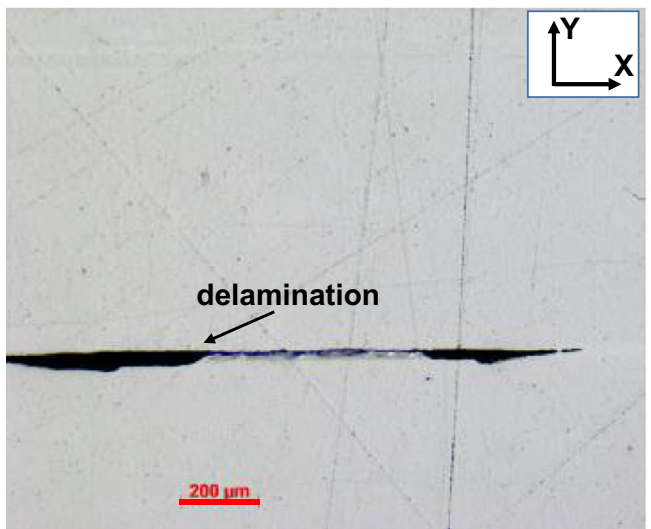

b)

Fig. 5 Microscopic damage observations at the highest loading ratio applied $(r=68 \%)$. a PA12; b PA6 
method. The function of the linear model is expressed by

$r=1-B \log _{10}\left(\mathrm{~N}_{10}\right)$

where $B$ is the degradation rate. The linear model plotted in Fig. $4 \mathrm{~b}$ for the PA6 is shown in Eq. (6):

$r=1.1323-0.078 \log _{10}\left(\mathrm{~N}_{10}\right)$, with $R^{2}=0.922$

For each build orientation, the $R$-square values of the normalized model were greater than 0.92 . This means that $92 \%$ of the response variance is accounted for by the linear model. In addition, the value of the inverse degradation rate $|1 / B|$ was also studied previously to compare the fatigue properties of studied materials to those obtained by injection moulding [14]. In fact, the materials with ratio $|1 / B|$ is the highest present longer the end-of-life and smaller degradation rate. The value $|1 / B|$ of pseudo-Wohler's curves of studied PA6 was obtained $12.8 \pm 0.2$ that is $20-30 \%$ lower than IM of PA6 [14].

\section{Conclusion}

This work focused on the experimental analysis of the quasistatic and cyclic flexural properties of PA6 and PA12 obtained by FFF. The following conclusions could be drawn:

1. Naturally, the mechanical and fatigue properties of the $3 \mathrm{D}$ printed polymer specimens can vary according to not only its porosity and pore characteristics. It can also depend on the degree of crystallinity. In spite of their four times lower degree of crystallinity, PA12 specimens are four times more resistant and three times stiffer than the PA6 ones. This could be explained by its chemical difference. The structure of PA6 could be modified by the manufacturer to give it better printability, but also, unfortunately, poorer mechanical properties.

2. The quasi-static flexural properties of PA12 manufactured by FFF highlight better characteristics compared to IM and extruded specimens than those of FFF printed PA6. Note that contrary to the FFF process, the elastic properties of PA6, obtained by the conventional techniques, are usually twice better than those of PA12 [25-31].

3. At lower stress levels in the visco-elastic domain and according to the $\mathrm{N}_{10}$ criterion of the end-of-life, the endurance diagram of PA12 and PA6 FFF specimens was obtained. In spite of almost amorphous state of PA12, it has a higher overall fatigue life in the considered testing range than the PA6 one. Only a few micro-delamination cracks were observed for PA12 that did not impact the fatigue performance.
Acknowledgements The authors would like to thank Benoit Pichereau and Linamaria Gallegos from Arts et Métiers, Angers Campus, for helpful discussions and technical support.

Funding This study was supported by the French-Russian collaboration project and financed by Ministry of Education and Science of the Russian Federation as part of the implementation of the state task No. 0707-20200034.

Availability of data and material The data that support the findings of this study are available from the corresponding author, upon reasonable request.

Code availability Not applicable

\section{Declarations}

Conflict of interest The authors declare no competing interests.

\section{References}

1. Mohamed OA, Masood SH, Bhowmik JL (2015) Optimization of fused deposition modeling process parameters: a review of current research and future prospects. Adv Manuf 3:42-53. https://doi.org/ 10.1007/s40436-014-0097-7

2. Safai L, Cuellar JS, Smit G, Zadpoor AA (2019) A review of the fatigue behavior of 3D printed polymers. Adv Manuf 28:87-97. https://doi.org/10.1016/J.ADDMA.2019.03.023

3. Ziemian C, Sharma M, Ziemian S (2012) Anisotropic mechanical properties of ABS parts fabricated by fused deposition modelling. INTECH Open Access Publisher

4. Ziemian S, Okwara M, Ziemian CW (2015) Tensile and fatigue behavior of layered acrylonitrile butadiene styrene. Rapid Prototyp J 21(3):270-278

5. Ziemian C, Ziemian R, Haile K (2016) Characterization of stiffness degradation caused by fatigue damage of additive manufactured parts. Mater Des 109(Supplement C):209-218. https://doi.org/10. 1016/j.matdes

6. Forster AM (2015) Materials testing standards for additive manufacturing of polymer materials: state of the art and standards applicability. us department of commerce. National Institute of Standards and. Technology

7. Sood AK, Ohdar RK, Mahapatra SS (2010) Parametric appraisal of mechanical property of fused deposition modelling processed parts. Mater Des 31(1):287-295

8. Afrose MF, Masood SH, Lovenitti P, Nikzad M, Sbarski I (2016) Effects of part build orientations on fatigue behaviour of FDMProcessed PLA material. Prog Addit Manuf 1(1-2):21-28

9. Shanmugam V, Das O, Babu K, Marimuthu U, Veerasimman A, Johnson DJ, Neisiany RE, Hedenqvist MS, Ramakrishna S, Berto F (2021) Fatigue behaviour of FDM-3D printed polymers, polymeric composites and architected cellular materials. Int J Fatigue 143: 106007

10. Berto F, Torgersen J, Campagnolo A (2017) A review of the fatigue strength of structural materials under multiaxial loading in terms of the local energy density. Eng Solid Mech 5(4):245-270

11. Harris M, Potgieter J, Archer R, Arif KM (2019) Effect of material and process specific factors on the strength of printed parts in fused filament fabrication: a review of recent developments. PMC 12(10): 1664. https://doi.org/10.3390/ma12101664 
12. Fitzharris ER, Watanabe N, Rosen DW, Shofner M (2018) Effects of material properties on warpage in fused deposition modeling parts. Int J Adv Manuf Technol 95:2059-2070

13. Vaes D, Coppens M, Goderis B, Zoetelief W, Van Puyvelde P (2019) Assessment of crystallinity development during fused filament fabrication through fast scanning chip calorimetry. Appl Sci 9(13):2676. https://doi.org/10.3390/app9132676

14. Terekhina S, Tarasova T, Egorov S, Skornyakov I, Guillaumat L, Hattali ML (2020) The effect of build orientation on both flexural quasi-static and fatigue behaviours of filament deposited PA6 polymer. Int J Fatigue 140:105825

15. Terekhina S, Tarasova T, Egorov S, Guillaumat L, Hattali ML (2020) On the difference in material structure and fatigue properties of polyamide specimens produced by fused filament fabrication and selective laser sintering. Int J Adv Manuf Technol 111:93-107

16. ISO 178:2010, Plastics - Determination of flexural properties, ISO/ TC 61/SC 2, Ed. Switzerland: International Standards Organization, 2010.

17. ASTM D3418-15, Standard test method for transition temperatures and enthalpies of fusion and crystallization of polymers by differential scanning calorimetry. ASTM Volume 08.02 Plastics (II): D3222-D5083. Available: www.astm.org.

18. Blaine RL. Thermal Applications Note, s.l.: Polymer Heats of Fusion, 2002.

19. Dupin S (2012) Etude fondamentale de la transformation du polyamide 12 par frittage laser: mécanismes ohysico-chimiques et relations microstructures/propriétés. Dissertation, Lyon, INSA de Lyon

20. ASTM D7774-12, Standard test method for flexural fatigue properties of plastics, D20.10.24, Ed. West Conshohocken, PA: ASTM International, 2013. [Online]. Available: www.astm.org.

21. Rennie AR (1999) Mechanical properties and testing of polymers. Kluwer Academic Publisher, Ed. by Swallowe GM

22. HW Starkweather HW, Moore JRGE, Hansen JE, Roder TM, Brooks RE. (1956) Effect of crystallinity on the properties of nylons. J Polym Sci 21:189-204
23. Stratasys, 2019. The Complete Guide to injection molding plastics parts. [En ligne] Available at: https://www.plastopialtd.com/pa6/

24. Efunda, 2019. Polyamide. Material properties. Datasheet. [En ligne] Available at https://www.efunda.com/materials/polymers/ properties/polymer_datasheet.cfm?MajorID=PA\&MinorID=2

25. Akkapeddi MK Microstructural effects on the properties of injected molded nylon 6 nanocomposites. SPE/ANTEC 1999. Proceedings.

26. Jogi BF, Sawant M, Brahmankar PK, Ratna D, Tarhekar MC. Study of mechanical and crystalline behavior of polyamide 6/Hytrel/crbon nanotubes (CNT) based polymer composites. Procedia Mater Sci 2014; 6: 805 - 811

27. Laminated Plastics, 2019. Technical data sheet. [En ligne] Available at: https://aminatedplastics.com/nylon.pdf.

28. Ozmen SC, Ozkoc G, Serhatli E (2019) Thermal, mechanical and physical properties of chain extended recycled polyamide 6 via reactive extrusion: effect of chain extender types. Polym Degrad Stab 162:76-84

29. Tuan Noraihan Azila Tuan R et al. Comparison of mechanical properties for polyamide 12 composite-based biomaterials fabricated by fused filament fabrication and injection molding. AIP Conference Proceedings 2016; 1791(1), AIP Publishing.

30. Efunda, 2019. Polyamide. Material properties. Datasheet. [En ligne] Available at : https://www.efunda.com/materials/polymers/ properties/polymer_datasheet.cfm?MajorID=PA\&MinorID=81

31. Biron M, 2018. Thermoplastics and thermoplastic composites. s.1.: William Andrew.

32. Roudet F, Desplanques Y, Degallaix S (2002) Fatigue of glass/ epoxy composite in three-point-bending with predominant shearing. Int J Fatigue 24:327-337

33. Lesser AJ (1995) Changes in mechanical behavior during fatigue of semicrystalline thermoplastics. J Appl Polym Sci 58(5):869-879

Publisher's note Springer Nature remains neutral with regard to jurisdictional claims in published maps and institutional affiliations. 